\title{
小学体育教学中学生学习兴趣的提升探究
}

陈俊炳

普宁市麒麟镇蔡口小学

DOI:10.32629/jief.v2i11.2473

[摘 要] 在小学体育课程中, 随着新课改的推进, 教师在教学时不仅需要帮助学生建立体育锻炼的意识, 更加需要进行科学合理的教学安排, 帮助学生培养体育学习的兴趣, 从而培养他们养成体育锻炼的习惯, 培养他们德智体美劳全面发展, 为他们的成长打下良好的基础。本文对 如何在小学体育教学过程中提高学生的学习兴趣进行了相关的探究, 提出了采取小组竞争、进行趣味教学、开展现场教学。

[关键词] 小学体育; 教学探究; 教学策略

中图分类号: G623 文献标识码: A

对于小学生而言, 他们正处于身体发展的阶段, 因此教师在对他们 进行体育训练的过程中, 应当重视他们的生理特点, 帮助他们建立良好 的身体素质, 引导他们进行正确的锻炼方式, 从而更好地提高他们的身 体素质。但是在体育教学过程中, 学生对于体育知识的兴趣并不是十分 浓厚, 因此教师要不断发掘新型的教学方式, 从而提高学生的学习兴趣。

\section{1 采取小组竞争提升学习兴趣}

小学生在这个阶段往往具有十分浓烈的好奇心, 而相对其他课程而 言, 体育课程大部分都在室外进行, 因此对于提高学生的学习兴趣是有 一定的好处的, 可以极大地提高学生的学习热情。需要注意的是, 学生 在这个阶段有较高的攀比心理, 他们虽然年纪比较小, 但是他们的自尊 心十分高, 也想吸引别人的注意, 从而满足自己的成就感, 并且教师在 进行教学的过程中, 可以利用学生的这个心理特点, 在学生之间加入竞 争的元素, 提高学生的学习效率。

比如教师在课堂中可以对班级的学生进行分组, 根据他们的特点, 合理地安排他们的团队, 然后在讲解完相关的知识之后, 小组之间形成 一种竞争的关系, 可以提高他们的学习效率, 帮助他们理解和掌握相关 的体育知识。在进行短跑训练的过程中, 教师可以先将学生根据身体素 质进行分组, 然后告诉他们, 接下来的时间是小组竞争的环节, 将会举 办一场小小的短跑接力比赛, 取得第一的小组可以有一定的物质上的奖 励, 比如一个练习本或者一支笔, 乃至他们喜欢的贴纸, 从而引导他们 为自己的小组拼尽全力, 取得好名次, 获得荣誉感。然后教师在对学生 们进行关于短跑知识的讲解, 学生这个时候的注意力就会高度集中, 从 而提高学生的学习效率, 激发学生的学习兴趣。

\section{2 进行趣味教学提升学习兴趣}

小学生对于抽象的知识的兴趣并不是很高, 影响教师可以通过讲解 一些童话故事, 或者进行一些趣味性的活动, 来帮助学生理解抽象的知 识, 提高他们的学习兴趣。

学生对于故事的兴趣往往比较高, 因此教师在进行跳跃教学的时候, 可以先给学生教关于小青蛙的故事, 在讲述的过程中可以引导学生模仿 青蛙跳跃, 从而引发他们对于学习的兴趣和好奇心, 同时学生在进行模 仿的过程中, 教师在他们尝试的过程中发现他们动作存在的问题, 然后 对于其中的要点和技巧进行相关的讲解, 可以提高他们的学习效率, 帮 助学生更好的改变动作上的失误。然后教师可以组织学生进行跳跃的训 练, 在训练的过程中可以引导他们主动思考, 如何可以跳得更高更远, 从而培养他们自主思考和探究的能力, 在传统的教学过程中, 学生经常 会对教师枯燥无味地讲述变得不感兴趣, 通过这种趣味性的教学, 教师
不仅可以帮助学生提高学习兴趣, 而且还可以在活动中发现学生们存在 的问题, 及时地进行改正, 帮助学生更好的成长。

\section{3 开展现场教学提升学习兴趣}

在传统的体育教学课程的安排上, 教师往往会选择先将比较抽象的 理论知识讲解给学生们, 在学生们理解和掌握之后再进行实践训练, 但 是在讲解的过程中, 学生往往会因为不感兴趣或者教师讲的过于枯燥, 学生理解上比较困难, 从而丧失了学习的兴趣, 降低了学生的学习效率。 因此教师可以采取另一种教学思路, 比如先让学生进行实践, 然后教师 通过观察学生们在实践过程中出现的问题进行分析和思考, 然后找到相 应的解决对策, 并且根据学生可能存在的危险, 找到需要注意的地方, 再对学生们进行讲解, 通过这样的方式不仅可以提高学生的学习兴趣, 也可以有效提高教学质量和效率。

比如在进行关于足球的讲解过程中, 教师可以先让学生自由地进行 足球活动, 然后教师在一旁通过观察学生在踢球时的动作, 找到他们存 在的动作错误, 和在踢足球过程中容易发生的危险, 然后再对学生进行 系统地讲解, 在讲解的时候, 可以根据某一个学生的作为例子, 加深学 生的理解和记忆, 通过这样的教学方式, 不仅可以帮助学生更好地理解 抽象的体育知识, 也可以提升他们学习的兴趣, 提高教学质量和教学效 率, 然后在讲解完相应的体育知识之后, 可以组织学生在一起进行实践 活动, 让学生们体会到理论和实践相结合的道理。

总而言之, 小学生的成长已经不再是以往的传统教学模式就可以达 到现有的需求的, 需要教师在教学过程中不断地进行创新和提高教学质 量, 采取新型的、合理的教学手段, 帮助学生提高学习的兴趣, 为之后 的学习打下良好的基础, 帮助学生德智体美劳全面发展, 与此同时教师 也要不断提升自己的素养和教学能力, 从而将学生培养成祖国需要的新 型人才。希望通过本文的探究, 可以对广大的体育教师在教学过程中提 供一定的帮助。

\section{[参考文献]}

[1]王立军.探究如何在小学体育教学中培养学生的学习兴趣 [J].中 国校外教育:上旬,2017,000(009):P.19-20.

[2]郡丹丹.探究如何在小学体育教学中培养学生的学习兴趣 [J]. 考 试周刊,2018,000(037):142.

[3] 李汀. 小学体育课堂构建优教乐学氛围的策略 [J]. 知识窗(教师 版),2020(09):39. 